\title{
The Analysis of the Financial Risk \\ Compensation Mechanism of Sub-funds of Poverty Alleviation Industry of Guizhou Poverty Alleviation Investment Fund by Using Game Theory
}

\section{Ziyan Wang Yiming Cai}

School of Finance, Guizhou University of Finance and Economics, Guiyang Guizhou 550025 , China

\begin{abstract}
This paper analyses the risk compensation mechanism of Sub-funds of poverty alleviation Industry of Guizhou poverty alleviation investment fund by using game theory. And we analyze the two processes of cooperative game and dynamic game of government and financial institution respectively. Then we concluded that government and financial institutions can achieve win-win results in such risk compensation_ — both to expand the business of financial institutions so as to enhance the profit, also can bring social benefits.
\end{abstract}

\section{Keywords}

Risk compensation; Cooperative game; Dynamic game

\section{贵州脱贫攻坚投资基金扶贫产业子基金 金融风险补偿博弯分析}

\section{王资燕 蔡一鸣}

贵州财经大学金融学院, 贵阳 550025, 中国

摘要: 本文利用博恋理论对贵州脱贫攻坚投资基金扶贫产业子基金金融风险补偿进行分析, 分别从政府和金融机构合作博弯和动态博弯的两个过程着手分析，进而推断出在这个风险补 偿机制下，政府和金融机构在博弯下能取得共赢的局面，既能扩大金融机构业务从而提升收 益, 也能带来社会效益。

关键词: 风险补偿机制 ; 合作博亦 ; 动态博亦 


\section{1. 文献综述}

所国内有不少学者做过对扶贫产 业问题的研究, 2014 年高军, 李忠 东对甘肃扶贫攻坚探索后发现了许多 问题，其中资金不足产业机构单一问 题尤其突出, 他指出政府应当积极干 涉此类问题。孙文韬，盛洁（2016） 对于银行和政府的合作进行探讨, 他 们认为在扶贫攻坚的问题上, 政府和 银行合作起来，各自利用各自的优 势, 把两者优势有效的结合起来创造 更大的效应。

这个结合就是建立风险补偿机 制，丁小强（2016）指出产业扶贫面 临着资金周转不足和风险能力防范不 足的问题，金融机构不愿意出资支持 扶贫工作，建立风险补偿机制可以减 少银行投资损失, 一定程度上消除银 行出资的顾虑, 推动经济发展。对于 这一类产业的风险补偿机制最开始都 是对担保机构风险补偿, 后来渐渐的 发展为针对银行的风险补偿, 康彦 华, 赵映光（2011）对青岛小企业贷 款风向补偿机制演变分析得出风险补 偿针对银行的效果要比针对担保机构 的效果要好一些。李铁宁, 罗建华等

（2016）对政银合作的风险补偿机制 进行了更加深层次的分析, 他们建立 了激励补偿和风险补偿都存在的模 型, 再计算出政府担保最优的补偿机 制, 得出如下结论: 这种机制比以往 的政府补偿机制要更好, 使各个方面 的效益有明显的提高。

政府和金融机构通过风险补偿机 制作用结合在一起创造更大的效应, 这个作用机制已经被广大学者所肯 定, 对其的研究也不在少数, 但是针 对扶贫攻坚方面的风险补偿机制的研 究还有很多的空白。本文在这些研究 为基础下用博亦理论对贵州脱贫攻坚
投资基金扶贫产业子基金金融风险补 偿机制进行分析, 给扶贫产业风险补 偿机制的完善提供一定的参考。

\section{2. 贵州省脱贫攻坚投资基金扶贫产 业子基金概述}

贵州省脱贫攻坚投资基金扶贫产 业子基金是是由省财政厅委托贵州脱 贫攻坚投资基金有限责任公司会同金 融机构、贵州省贵金瑞和创业投资管 理有限责任公司共同发起的有限合伙 制基金，委托贵金瑞和创业投资管理 有限责任公司作为该基金的有限合伙 企业的执行事务。该基金拟财政性和 金融机构按照 $15 \%$ ：85\%的比例出 资, 规模初设 1200 亿元, 其中财政 性资金 180 亿元，银行等金融机构资 金 1020 亿元。基金建设的目的是推 动贵州农业等产业的发展, 达到经济 发展的目的。

贵州省脱贫攻坚投资基金扶贫产 业子基金主要投资在贵州省境内注册 纳税的, 能够带动农民增收, 就业, 脱贫的在贵州省经营期限不低于基金 投资存续期的法人企业。基金采取募 投制，投资项目成熟一个投放一个， 第一期计划募集资金 588 亿元，财政 性资金出资 88 亿元，金融机构出资 500 亿元，出资金融机构预期年化投 资率不超过人民银行同期同档次贷款 基准利率下浮 $5 \%$ 以上。并且为提高 资金的使用效率，投资项目获得批准 后由脱贫基金公司发起募资，财政资 金和金融机构资金同步到位。

基金主要投资于带动农民脱贫的 产业, 包括山地特色高效农业、林业 产业、加工业、农业服务化、农产品 流通化、农业信息化、旅游业、大健 康产业、农村互联网产业等能够促进 农村一二三产业融合发展的产业, 推 
动贵州经济增长, 缩小贫富差距。若 出现风险代偿的问题按照 “4321” 的 比例承担分担风险, 即: 所在地政策 性金融机构承担 $40 \%$, 省财政补偿 金承担 $30 \%$, 金融机构承担 $20 \%$, 同级财政风险补偿金承担 $10 \%$

\section{3. 贵州省脱贫攻坚投资基金扶贫产业 子基金面临主要风险}

\section{1 流动性风险}

产业基金主要投资农业类产业， 这一类投资的投资期限长，投入资金 大，现金流不稳定，这些因素使资金 链断裂的风险大大提高。如果出现资 金问题，这一类固定资产又很难变 现，给项目造成的损失会不可估量。 但是充足的现金流会减少这一类风 险，所以银行更应该加大投资力度。

\section{2 市场风险}

投资项目的产品在市场的销售过 程里, 产品价格会有一定的波动, 这 个价格的变化受到供求量变化、政策 的改变、经济情况变动影响的。这个 变化如果超出的预期的范围, 便会产 生一定的风险，是投资的项目可能蒙 受损失 ${ }^{[1]}$ 。随着国内市场化机制日出 完善, 市场风险是不可忽略的一类风 险。

\section{4. 如何对贵州省脱贫攻坚投资基金 扶贫产业子基金面临主要风险进 行风险补偿}

列扶贫项目的投资可以开发经济 发展生产, 开发经济, 有一定的经济 利益和社会效益, 但是同时也面临着 各种各样的风险, 这些风险从一定程
度上削减了收益, 也给扶贫融资带来 困难。所以政府参与其中解决这个问 题，给与金融机构融资一定的风险补 偿, 并且引入政策性担保机构分担风 险，提升金融机构抗风险能力，扩大 金融机构投资 ${ }^{[2]}$ 。

\section{1 设立风险补偿金}

扶贫产业工程浩大，资金需求量 大，设立风险补偿金鼓励金融机构出 资, 能有效解决资金问题。风险补偿 金在最开始运用的时候并不是给与银 行一定风险补偿, 而是更多的投向担 保机构和一些大企业, 但是最后的并 没有好的效果，风险补偿金演变到现 在更多的是针对银行 ${ }^{[3]}$ 。文中产业子 基金就是政府针对银行等金融机构设 立风险补偿金, 给与银行一定的风险 补偿以刺激银行等金融机构对基金的 投资。这个补偿金是由省财政性资金 和各个地方财政资金组成的。当某些 项目发生亏损时，风险补偿金参与一 定的损失承担，减少金融机构不良资 产的比率。其中风险补偿金的代偿比 例如下图所示:

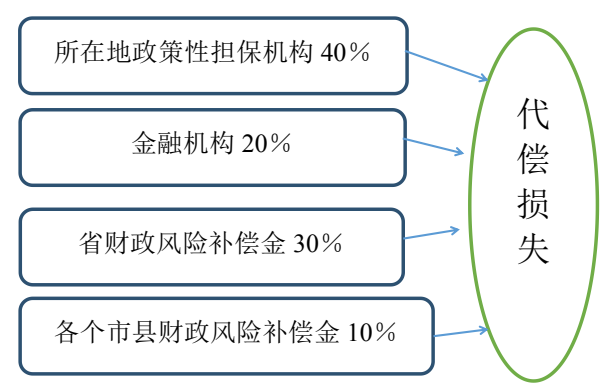

\section{2 机构担保奖励}

对于符合要求的项目申请担 保, 建立担保机构, 政府, 银行三者 风险共担, 收益共享的机制。给与担 
保机构一定的奖励或者给担保机构一 定的风险资金支持，加大担保机构对 投资项目担保力度。但是由于各个项 目所申请担保情况有区别，而且基金 运行在初始阶段, 各个项目还未正式 开始，后文暂且不考虑机构担保奖 励。

\section{5. 政府、金融机构合作博弃分析}

由于贵州脱贫攻坚投资基金扶贫 产业子基金刚成立不久（17 年 初），项目实施还处于一个初级阶 段, 尚未收集到有效数据, 故文章先 进行理论分析。

扶贫项目需要较大的资金支持, 但是由于其潜在的风险，银行的资金 往往不会投入其中，这使贵州一些产 业融资困难 ${ }^{[4]}$ 。政府插手其中, 鼓励 银行出钱融资, 可以有效改善融资困 难的局面。

目前, 贵州扶贫工作需要大量资 金融入，项目的风险也较高，银行不 愿意将资金融入其中 ${ }^{[5]}$ ，二扶贫又是 政府的工作，政府出手干预，在其中 起到推动作用，从政策上和资金上支 持银行融资, 即可以推进银行扶贫工 作，产生社会效益，也可以给银行带 来经济效益, 两者形成了一个合作的 联盟。这个过程可以看作是一个合作 博弯的过程, 政府和银行作为合作博 弯的主体, 在风险补偿机制这一外力 的作用下, 双方做出的选择使博亦双 方的利益都增加 ${ }^{[6]}$ 。不妨用 shapley 值来分析合作博弯的过程:

\section{1 变量定义}

（1） $\mathrm{n}$ : 代表 $\mathrm{n}$ 个参与者（政府 和银行两个参与者）。
(2) $\mathrm{N}: \mathrm{n}$ 个参与者组成的集 合。

（3） S: n 个参与者组成的合作 同盟。

(4) $\mathrm{v}(\mathrm{S}): \mathrm{S}$ 同盟合作后获得最 大收益。

(5) $\varphi \mathrm{i}(\mathrm{V})$ : 参与者 $\mathrm{i}$ 的收益。

\section{2 模型构建}

政府：补助银行风险补偿金 $\mathrm{I}_{1}$ （由省财政资金地方性财政资金共同 出资的部分），投资会推动经济发 展, 提高人民生活水平, 给社会带来 一定的效益, 设给社会提供效益系数 为 $\delta$ 。

银行: 银行出资为 $\mathrm{I}_{2}$, 银行贷款 利率 $\mathrm{r}_{1}$, 存款利率 $\mathrm{r}_{0}$ 。并且投资企业 的生产函数 $\mathrm{Y}=\mathrm{AL}^{\alpha} \mathrm{I}_{2}{ }^{\beta}$ 。

在该合作博亦的过程中, 参与者 集合为 $\mathrm{N}=(1,2)$, 两个参与者分 别是政府和银行。在这样两个合作弯

$(\mathrm{N}, \mathrm{v})$, 做出如下 shapley 值公 式。

$\varphi \mathrm{i}(\mathrm{V})=\sum_{\mathrm{S} \subset \mathrm{N}} \frac{(|\mathrm{S}|-1) \cdot(n-|S|) !}{n !} \times[v(S)-v(S-\{i\})]$

公式中:

（1） $\mathrm{s}=|\mathrm{S}| ， \mathrm{n}=|\mathrm{N}|$ （S: 所有参 与者集合, $\mathrm{N}$ 任意有限载体);

(2) 参与者 $\mathrm{i}$ 对集合 $\mathrm{S}$ 的贡献值:

$$
[v(S)-v(S-\{i\})] 。
$$

政府和银行在这种风险补偿机制 下的特征函数如下:

$\mathrm{v}(1)$ :政府参与基金融资过程，银 行不参与: 


$$
\begin{aligned}
\mathrm{v}(1) & =\mathrm{AL}^{\alpha} \mathrm{I}_{1}{ }^{\beta}-\mathrm{C}(\mathrm{L})+\mathrm{G}\left(\mathrm{I}_{1}\right)-\mathrm{C}\left(\mathrm{I}_{1}\right) \\
& =\mathrm{AL}^{\alpha}{ }^{\alpha} \mathrm{I}_{1}{ }^{\beta}-\mathrm{LP}+\sigma\left(\mathrm{AL}{ }^{\alpha} \mathrm{I}_{1}{ }^{\beta}\right)
\end{aligned}
$$

$\mathrm{v}(2)$ : 政府不参与融资过程, 也不 给与银行融资任何补偿, 银行投入 I2 到基金:

$$
\begin{aligned}
\mathrm{v}(2) & =\mathrm{AL}^{\alpha} \mathrm{I}_{2}{ }^{\beta}-\mathrm{C}(\mathrm{L})-\mathrm{I}_{2} \mathrm{r}_{0} \\
& =\mathrm{AL}^{\alpha} \mathrm{I}_{2}{ }^{\beta}-\mathrm{LP}-\mathrm{I}_{2} \mathrm{r}_{0}+\mathrm{I}_{2} \mathrm{r}_{1}
\end{aligned}
$$

$\mathrm{v}(1,2)$ :在这种风险补偿机制下, 银行和政府合作的情况系下的特征函 数。

$$
\begin{aligned}
& \mathrm{v}(1,2)=\mathrm{AL}^{\alpha} \mathrm{I}_{2}^{\beta}-\mathrm{LP}+\sigma\left(\mathrm{AL}^{\alpha} \mathrm{I}_{1}^{\beta}\right)-\mathrm{I}_{1} \mathrm{r}_{01} \\
& -\mathrm{I}_{2} \mathrm{r}_{0}+\mathrm{I}_{2} \mathrm{r}_{1}
\end{aligned}
$$

\section{3 结果分析}

将特征函数代到 shapley 公式:

$$
\varphi \mathrm{i}(\mathrm{V})=\sum_{\mathrm{S} \subset \mathrm{N}} \frac{(|\mathrm{S}|-1) !(n-|S|) !}{n !} \times[v(S)-v(S-\{i\})]
$$

得:

$$
\begin{aligned}
& \varphi_{1}(\mathrm{v})=\frac{1}{2}\left[\mathrm{AL}^{\alpha} \mathrm{I}_{1}^{\beta}+\sigma\left(\mathrm{A}_{\mathrm{I}_{1}} \mathrm{~L}^{\alpha} \mathrm{I}_{1}^{\beta}\right)+\mathrm{AL}^{\alpha} \mathrm{I}_{2}{ }^{\beta}-\mathrm{I}_{1} \mathrm{r}_{0}-\mathrm{LP}\right] \\
& \varphi_{2}(\mathrm{v})=\mathrm{AI}_{2}{ }^{\alpha} \mathrm{L}^{\beta}-\frac{1}{2} \mathrm{LP}-\frac{1}{2}\left(\mathrm{AL}^{\alpha} \mathrm{I}_{1}{ }^{\beta}\right)
\end{aligned}
$$

所以在此博弯中政府的收益比例为:

$$
\gamma_{1}=\frac{\varphi_{1}}{\varphi_{1}+\varphi_{2}}
$$

金融机构收益比例为:

$$
\gamma_{2}=\frac{\varphi_{2}}{\varphi_{1}+\varphi_{2}}
$$

以上得出的政府和金融机构收 益特征函数可以得出, 政府和金融机 构合作博弯时各方的利益受多个元素 影响, 一方面政府收益与其提供的风 险补偿金的多少和社会效应系数有 关, 都是随两者的增加而增加, 所以
政府投入的补偿资金越大，其收益情 况也是相应增长的。另一方面来说, 银行对基金投入资金越多其相应的收 益也是越大的。

（1）为了让基金更好的可持续 发展，使政府和金融机构都能增加收 益, 政府和金融机构合作通过做大 $\gamma$ 表达式中的 $\phi_{1}+\phi_{2}$ 的绝对值从而增 加 $\gamma 1$ 和 $\gamma 2$ 的绝对值这一个方面政 府与金融机构是同一利益的。

（2）第二个策略就是各方通过 增加 $\gamma_{1}$ 和 $\gamma_{2}$ 中的分子中的 $\phi$, 也就 是他们在博弯中尽量增加自己收益来 增加博弯中收益占比 $\gamma$, 这是不完全 信息的动态博弯, 在后文详细分析。

\section{4 动态博弯分析}

在之前的基础上，政府为了金融 机构能够继续更大力度的支持扶贫子 基金，他会做出一定让利给金融机 构，金融机构会根据这个让利情况来 决定自己是否加大对基金的投入，政 府让利的目的是为了引入金融机构对 基金的投资，但是基金投资所赚取的 利益又是不确定性的, 所以这是一个 不完全信息的动态博弯 ${ }^{[7]}$ 。

\subsection{1 基本假设}

（1）金融机构追加投资为 $\mathrm{I}_{1}$ （这个资金是金融机构收到政府让利 信号后扩大投资部分），银行贷款和 存款利率分别为 $\mathrm{r}_{0}$ 和 $\mathrm{r}_{1}$, 金融机构投 资期望收益率为 $r_{2}$, 金融机构出现风 险的概率为 $r_{3}$ 以及亏损时候的资本比 例为 $\mathrm{k}$ ，金融机构自己搜集资料估算 投资失败概率为 $\mathrm{q}$ 。

（2）政府让利的资金为 $\mathrm{I}_{2}$ （这 里资金的形式替代其他让利形式）。 


\subsection{2 动态博亦分析}

金融机构和银行在博弯中都想提 高自身所得收益，增加自身收益占总 收益的比重, 我们可以用动态博弯模 型来分析这个问题。在博弯中，政府 为了能让金融机构投入更大力度，便 出资设立风险补偿机制，促使金融机 构加大投入力度，这个风险补偿机制 可以看成政府让利给银行。在博弯初 期金融机构只有靠自己搜集的信息和 政府给出的让利情况来决定自己的投 资情况。同时金融机构还要考虑投资 后的风险 ${ }^{[8]}$ 。

所以该博弯顺序为:

(1)政府做出选择给金融机构让 利 I 或者不让利。

(2)金融机构根据让利情况和风 险判断选择是否投资。

在这种情况下银行选择投资收益 期望为: $E_{a}=I_{1} r_{3}(1-q)+I_{2}\left(r_{1}-r_{0}\right)-q I_{1} k$

若银行选择不追加投资则其收益 期望为: $E_{b}=I_{1}\left(r_{1}-r_{0}\right)$

所以若要银行投入更大的资金则 必须满足 $\mathrm{E}_{\mathrm{a}}>\mathrm{E}_{\mathrm{b}}$, 即: 如果满足 $\mathrm{E}_{\mathrm{a}}=\mathrm{I}_{1} \mathrm{r}_{3}(1-\mathrm{q})+\mathrm{I}_{2}\left(\mathrm{r}_{1}-\mathrm{r}_{0}\right)-\mathrm{qI} \mathrm{I}_{1} \mathrm{k}>\mathrm{I}_{1}\left(\mathrm{r}_{1}-\mathrm{r}_{0}\right)$, 那 么银行会加大对扶贫项目投入的力 度。

\section{6. 结论}

综上所述，贵州脱贫攻坚投资基 金扶贫产业子基金的风险补偿机制把 政府和银行有机结合在一起, 给其中 的各方都带来正效益。政府在其中有 着不可或缺的作用，通过对金融机构 的补偿和对投资风险的分推，让金融 机构更大的投入扶贫产业，这一举措 是非常明智的。“十三五”规划时间 已经快到一半了，扶贫攻坚刻不容 缓, 政府和金融机构应当建设合理风
险分担, 利益分享机制, 才能健康可 持续开展扶贫攻坚工作。

\section{参考文献}

[1] 胡宜挺,罗必良. 我国农业市场风险 演化: 判断与评估 [J]. 农村经 济,2010,(04):10-13.

[2] 孙文蹈,盛洁. 论政府增信与银行授 信的合作实施路径 [J]. 财经界(学术 版）,2016,(17):28.

[3] 康彦华,赵映光. 金融类准公共产品 供给的制度设计与有效性分析青岛市小企业贷款风险补偿金案例 [J]. 金融发展研究,2011,(11):47-50.

[4] 施辉奎,刘尔思. 云南省产业扶贫融 资 问题 研 究 $[\mathrm{J}]$. 北方经 贸,2011,(03):46-47.

[5] 潘跃. 政府与非政府组织合作实施 村级扶贫规划 [N].人民日报,200512-20(002).

[6] 孙雅芳. 科技型中小企业贷款风险 补偿机制的博弯分析 [D]. 贵州财经 大学, 2016 .

[7] 甘甜. 西部地区创业投资发展中的 政府引导体系研究[D].四川省社会 科学院, 2014 .

[8] 孟晞,钟田丽. 小微企业与互助担保 组织的动态博弯研究 [J]. 财经问题 研究,2012,(12):117-121. 